\title{
6. ATHENA Integrated Project and the Mapping to International Standard ISO 15704
}

\author{
${ }^{1}$ David Chen, ${ }^{2}$ Thomas Knothe and ${ }^{3}$ Martin Zelm ${ }^{33}$ \\ ${ }^{1}$ LAP/GRAI, University Bordeaux 1, France, Email: chen@lap.u-bordeauxl.fr \\ ${ }^{2}$ FhG-IPK, Berlin, Germany, Email: Thomas.knothe@ipk.fhg.de \\ ${ }^{3}$ CIMOSA Association, Germany, Email: martin.zelm@cimosa.de
}

\begin{abstract}
This paper aims at presenting an overview of a European Integrated Project ATHENA to develop interoperability of enterprise applications and software. The first part of the paper tentatively maps the expected ATHENA solution components to ISO 15704 which is an important standard in the area of enterprise integration. This mapping allows categorising expected ATHENA research results according to ISO 15704 and evaluating the consistency and completeness of ATHENA solutions with respect to the ISO 15704 framework. The second part of the paper focuses on one solution component: enterprise modelling language. Possible use of UEML v1.0 in ATHENA A1 project and related work to develop UEML 2.0 in INTEROP NoE will be discussed. Conclusions are given at the end of the paper.
\end{abstract}

\section{INTRODUCTION}

ATHENA (Advanced Technologies for Interoperability of Heterogeneous Enterprise Networks and their Applications) aims at a holistic approach to develop interoperability of enterprise applications and software (Athena, 2004). It puts emphasis on the integrated research in three relevant domains to tackle interoperability problems: Enterprise Modelling (EM), Architecture and Platform (A\&P), and Ontologies (ONTO). ATHENA is actually a research program which consists of a set of projects, providing an overall interoperability solution in terms of prototypes, specifications, guidelines and best practices. One strategic orientation of ATHENA is to actively interact with standardisation bodies not only to use available standards whenever possible, but also to contribute further standard developments. As a starting point and at a high level abstraction, one relevant standard identified is the ISO 15704 (Requirements for Generalised Enterprise Architectures and Methodologies). This standard defines the generic concepts and components to use for enterprise integration and engineering projects. The first part of the paper tentatively evaluates, on the one hand the appropriateness of ISO 15704 to ATHENA approach; and on the other hand the consistency and the completeness of expected ATHENA solutions with respect to ISO 15704 framework. The mapping is developed on the basis of the analysis and comparison between ATHENA and ISO 15704. The second part of the paper is concerned with one ATHENA result

${ }^{33}$ Dr Martin Zelm is member of INTEROP Network of Excellence (NoE). 
component: the development of a language for modelling collaborative enterprises. The possible use of UEML will be discussed and on-going work outlined.

\section{ATHENA RESEARCH ACTIVITIES}

ATHENA Integrated Project consists of three action lines in which the activities take place. In Action Line $A$, the R\&D activities are carried out. Action Line B takes care of the community building. Action Line $\mathrm{C}$ hosts all management activities. Under Action line A, six research projects were defined and launched.

- Enterprise Modelling in the Context of Collaborative Enterprises (A1) develops methodologies for management and modelling of situated processes, flexible resource allocation and assignment for work management and execution monitoring. This project will enable scalable EM methodologies and infrastructures, repository services and portal server services.

- Cross-organisational Business Processes (A2) deals with modelling techniques to represent business processes of different organisations on a level that considers the privacy requirements of the involved partners. Such models, enriched with ontologies, will have two perspectives: an enterprise modelling aspect that assigns a process to its context in the enterprise, and a formal aspect to perform computational transformations to allow re-use of a process in a crossorganisational environment.

- Knowledge Support and Semantic Mediation Solutions (A3) aims at developing methods and tools for enterprise knowledge management, to support enterprise and application software interoperability. Focus is to use formal knowledge, organised in domain ontologies, to annotate the business processes and the software components in order to reconcile the possible mismatches in unanticipated cooperation activities.

- Interoperability Framework and Services for Networked Enterprises (A4) is concerned with the design and implementation of the infrastructure supporting interoperability adopting the Integrated Paradigm (i.e. where there is a standard format for all constituent sub-systems). The resulting toolset will be a set of software and engines that prepare any enterprise in the adoption and exploitation of interoperability support infrastructures.

- Planned and Customisable Service-Oriented Architectures (A5) will develop the understanding, tools and infrastructures required for service-oriented architectures. Although the project will consider existing infrastructures, an emphasis will be on the development of an environment for easier application development that natively provides better customisation.

- Model-driven and Adaptive Interoperability Architectures (A6) develops innovative solutions for the problem of sustaining interoperability through change and evolution, by providing dynamic and adaptive interoperability architecture approaches. It aims to advance the SoA in this field by applying the principles of model-driven, platform independent architecture specifications, and dynamic and autonomous federated architecture approaches, and the usage of agent technologies.

The research results will be structured in the ATHENA Interoperability Framework (AIF). The framework has three parts: (1) Conceptual Integration: definition of the 
Interoperability Reference Architecture and associated Interoperability Methodology; (2) Applicative Integration: definition of Best Practices, Guidelines and Handbooks; and (3) Technical Integration: definition of an Interoperability Support Infrastructure and tools, and the Technical Architecture.

\section{MAPPING ATHENA SOLUTION COMPONENTS TO ISO 15704 FRAMEWORK}

This section presents the GERAM (Generalised Enterprise Reference Architecture and Methodologies) framework defined in ISO 15704 and the mapping of ATHENA expected solution components to GERAM. Enterprise reference architectures and methodologies shall be capable of assisting and structuring the description, development, operation, and organisation of any conceivable enterprise entity, system, organisation, product, process, and their supporting technology (ISO 15704, 2000).

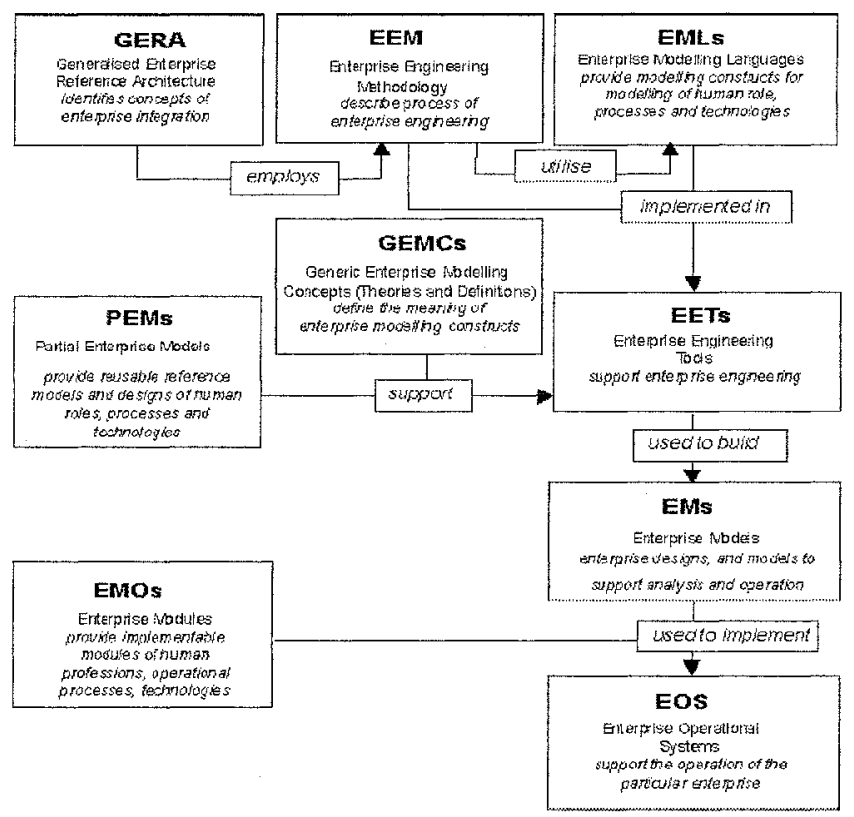

Figure 1. GERAM framework and its components (ISO 15704)

\subsection{Enterprise Reference Architecture}

(Generalised) Enterprise Reference Architecture (GERA) defines the enterprise related generic concepts recommended for use in enterprise engineering and integration projects. In ATHENA, the reference architecture aims at providing an appropriate categorisation of interoperability concepts in relations to developed technologies and applications. This research is carried out in project A4 (Interoperability Framework and Services for Networked Enterprises). The reference architecture will also provide the conceptual integration of research results of 
ATHENA and is embedded into the AIF. External standards and knowledge will also find their place in the reference architecture based on an analysis of their appropriateness for resolving interoperability issues (Athena, 2004).

\subsection{Enterprise Engineering Methodology}

In GERAM, Enterprise Engineering Methodologies (EEM) describes the processes of enterprise engineering. It provides methods of progression for every type of lifecycle activity. The ATHENA interoperability methodology is associated to the reference architecture and is also developed by project A4. This interoperability methodology is a set of methodologies with the following components: (1) A methodology for gathering, structuring and representing requirements, elaborated and used by Activity B4 (Dynamic Requirements Definition); (2) A methodology for collaborative business process modelling developed by project $\mathrm{Al}$ and will make use of UEML 1.0 for process model exchange; (3) A methodology specified by project A2 to model cross-organisational business processes and its implementation for execution; (4) A methodology for semantic annotations to business process models, developed by project A3. It will be based on a sound mathematical basis (such as Process Algebra, Situation Calculus or Graph Grammars) to make it independent of the specific user-oriented notations; (5) A methodology for specification of meta-modelling and to represent mature, interoperable and highquality web services. This methodology is elaborated by project A5; and (6) A methodology for implementing model-driven interoperable agent and peer-to-peer architectures. This research work will be developed by $\mathrm{A} 6$.

\subsection{Enterprise modelling language}

Enterprise Modelling Languages (EMLs) is an important component of GERAM. To develop enterprise models potentially more than one modelling language is needed (ISO 15704, 2000). In ATHENA, research on enterprise modelling languages vs. interoperability requirements will mainly be performed in projects A1, A2 and A3. These modelling languages will be used by interoperability methodology to build various models. More particularly: (1) Project A1 will develop Collaborative Enterprise Modelling Languages and Constructs based on UEML 1.0 meta model and others for process model exchange; (2) Project A2 focuses on the development of cross-organisational business process modelling language; (3) Project A3 aims at enterprise ontology modelling languages, semantic annotation techniques and languages. Results of A3 will be used in A1 and A2.

\subsection{Enterprise engineering tool}

Enterprise Engineering Tools (EETs) deploy enterprise-modelling languages in support of enterprise engineering methodologies, and specifically support the creation, use, and management of enterprise models (ISO 15704, 2000). The development of modelling tools in ATHENA is mainly concerned with projects A1, $\mathrm{A} 2$ and $\mathrm{A} 3$ as well as A6. Project A1 develops customisable tools for enabling the rapid adoption of collaborative business models, especially for use in SMEs. Project A2 develops (Cross-organisational Business Process) modelling tool to support the cross-organisational business process modelling language, methodology and its enactment. Project A3 will research an ontology-based semantic annotation and reconciliation tool to support the language and methodology developed for the same 
purpose to capture domain knowledge. It consists of tools supporting languages for Semantic Annotation of: (1) Business Processes, and (2) e-Services. Project A6 will use results of project A3. A semantic UML mapping tool - based on UMT (UML Model Transformation) open source toolkit will be developed. This tool is used to describe, integrate and relate platform independent service and information models, with a corresponding execution support on the platform specific level for UML system models.

\subsection{Enterprise modelling concepts}

(Generic) Enterprise Modelling Concepts (GEMCs) are the most generically used concepts and definitions of enterprise engineering and integration. The three forms of concept definition are, in increasing order of formality (ISO 15704, 2000): (1) glossaries, (2) meta-models, and (3) ontological theories. In ATHENA, generic enterprise modelling concepts are mainly developed in A1 and A2 projects in collaboration with A3. Besides of existing concepts identified in some standards (ISO 15704, EN/ISO 19439, EN/ISO 19440, etc.), concepts related to modelling interoperability requirements and solutions will be developed.

\subsection{Partial enterprise model}

Partial Enterprise Models (PEMs) (reusable reference models) are models which capture concepts common to many enterprises. The use of PEMs in enterprise modelling will increase modelling process efficiency (ISO 15704, 2000). One of the key results of ATHENA is to define a technologically neutral reference model that provides a stable, generic foundation for specific technical innovations. It will provide Guidelines and Best Practices, incorporating results from Technology Testing and implementation of this model. In particular the elaboration of this technologically neutral reference model will be based on semantic mediation solutions and provides components of interoperability infrastructures.

\subsection{Enterprise models}

Enterprise Models (EMs) are expressed in enterprise-modelling languages and are maintained (created, analysed, stored, distributed) using enterprise engineering tools (ISO 15704, 2000). In other words, enterprise models are models of particular enterprises and maybe created from enterprise reference models by instantiation or particularisation. In ATHENA, generic interoperability solutions proposed by A projects (A1-A6) will be moved to B5 (industrial test-sites) for testing and validation. To do this, enterprise models will be created to represent various industrial scenarios. For examples enterprise models representing collaborative enterprise interoperations (project $\mathrm{A} 1$ ) and cross-organisational business process interoperations (project A2) etc.

\subsection{Enterprise module}

Enterprise Modules (EMOs) are physical entities (systems, subsystems, software, hardware, and available human resources/professions) that can be utilised as common resources in enterprise engineering and integration. In general EMOs are implementations of partial models identified in the field as the basis of commonly required products for which there is a market. One set of enterprise modules of distinguished importance is the Integrating Infrastructure that implements the 
required Integrating. IT Services (ISO 15704, 2000). In ATHENA, the interoperability infrastructure is a key result developed by A4 in collaboration with some other A projects (for examples, Model-driven and Adaptable Interoperability Infrastructure by $\mathrm{A} 6$, and Intelligent Infrastructure to implement core Enterprise Modelling languages and meta-model templates by $\mathrm{A} 1$ ).

\subsection{Enterprise operational system}

Enterprise Operational Systems (EOS) support the operation of a particular enterprise. They are all the hardware and software needed to fulfil the enterprise objective and goals (ISO 15704, 2000). In ATHENA, four operational systems representing four scenarios will be implemented to validate project results: (1) Supply Chain Management in Aerospace industry (EADS), (2) e-Procurement in Furniture SMEs (AIDIMA), (3) Collaborative Product Development in Automotive (FIAT), and (4) Product Portfolio Management in Telecommunications (INTRACOM). For example, Project A1 will implement an operational system in INTRACOM to experience product portfolio management interoperability.

\subsection{Summary of mapping}

Figure 2 shows the mapping of ISO 15704 GERAM components to the ATHENA Interoperability Framework (AIF). Reference architecture, methodology, modelling languages and concepts as well as reference models are all conceptual elements. They are used to build particular enterprise models of studied company. Modelling tools are technology component which support the model construction. The 'particular' enterprise model(s) is conceptual model(s) and is applicative in a particular domain. Enterprise models are then implemented in operational systems with enterprise modules (infrastructure for example) to support operational systems that perform daily enterprise operations. Both enterprise modules and enterprise operational systems are concrete technical (technological) elements.

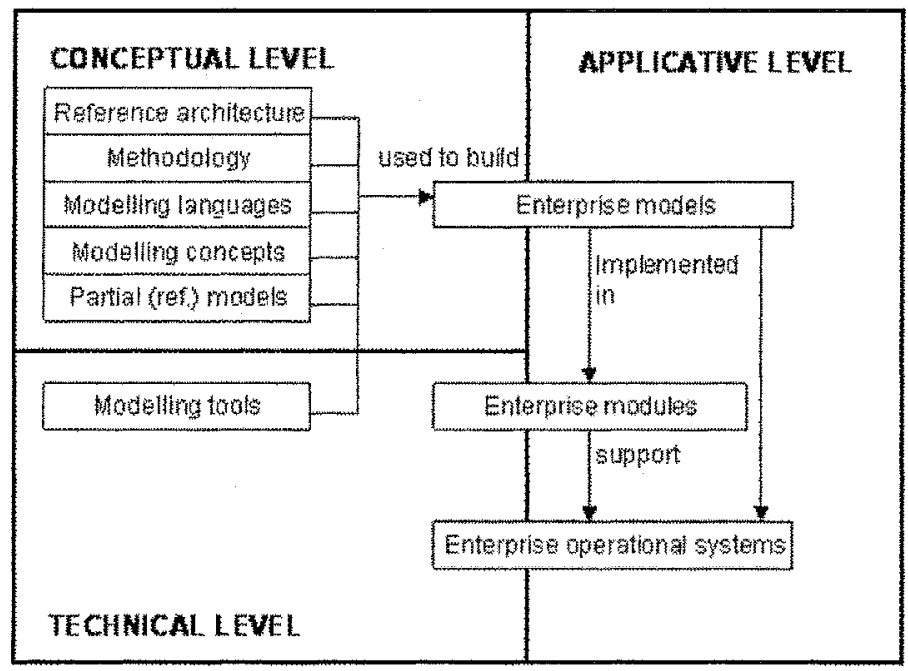

Figure 2. Mapping ISO 15704 framework to ATHENA Interoperability Framework 
The table below summarizes the mapping and intuitively gives an evaluation on the degree of conformance. The ' +++ ' means a perfect mapping and ' + ' indicates that the mapping is poor. ' ++ ' is in between.

Table 1: Summary of mapping

\begin{tabular}{|l|l|c|}
\hline ISO 15704 (GERAM Framework) & \multicolumn{1}{|c|}{ ATHENA Research solutions } & \\
\hline $\begin{array}{l}\text { Enterprise reference architecture } \\
\text { identifies concepts of enterprise } \\
\text { integrations }\end{array}$ & $\begin{array}{l}\text { ATHENA reference architecture (A4), } \\
\text { but also IT oriented architectures (A5, } \\
\text { A6) }\end{array}$ & ++ \\
\hline $\begin{array}{l}\text { Engineering methodology describes } \\
\text { process of enterprise engineering }\end{array}$ & $\begin{array}{l}\text { ATHENA methodologies (A4 but also } \\
\text { A1, A2, A3, A5, A6, B4) }\end{array}$ & +++ \\
\hline $\begin{array}{l}\text { Enterprise modelling languages } \\
\text { provide modelling constructs }\end{array}$ & $\begin{array}{l}\text { ATHENA enterprise modelling } \\
\text { languages (A1, A2 and A3 (semantic)) }\end{array}$ & +++ \\
\hline $\begin{array}{l}\text { Enterprise modelling tools support } \\
\text { enterprise modelling and engineering }\end{array}$ & $\begin{array}{l}\text { ATHENA enterprise modelling tools } \\
\text { (A1, A2, A3), also A6. }\end{array}$ & +++ \\
\hline $\begin{array}{l}\text { Enterprise modelling concepts } \\
\text { define meanings of enterprise } \\
\text { modelling constructs }\end{array}$ & $\begin{array}{l}\text { ATHENA enterprise modelling } \\
\text { concepts describing interoperability } \\
\text { requirements/solutions (A1, A2, A3) }\end{array}$ & +++ \\
\hline $\begin{array}{l}\text { Partial enterprise models provide } \\
\text { reusable reference models for } \\
\text { designing enterprise models }\end{array}$ & $\begin{array}{l}\text { ATHENA technologically neutral } \\
\text { reference model as generic foundation } \\
\text { for specific technical innovations (A4) }\end{array}$ & + \\
\hline $\begin{array}{l}\text { Enterprise models are designed for a } \\
\text { particular enterprise }\end{array}$ & $\begin{array}{l}\text { ATHENA enterprise models for testing } \\
\text { solutions (mainly A1, A2 and B5) }\end{array}$ & +++ \\
\hline $\begin{array}{l}\text { Enterprise modules are implemented } \\
\text { common enterprise system's } \\
\text { components }\end{array}$ & $\begin{array}{l}\text { ATHENA interoperability } \\
\text { infrastructure (A4) but also Model- } \\
\text { Driven adaptable infrastructure (A6) }\end{array}$ & $\begin{array}{l}\text { ATHENA operational systems } \\
\text { implemented by B5 in industrial sites } \\
\text { (testing) }\end{array}$ \\
\hline $\begin{array}{l}\text { Enterprise operational systems } \\
\text { supports operations of a particular } \\
\text { enterprise }\end{array}$ & ++ \\
\hline
\end{tabular}

It should be noted that ATHENA can provide more value to the ISO 15704 Standard via the thorough and consequent using of the GERAM concepts and terminologywhich might also lead to discovering open issues - as well as via a broad dissemination of the pilot and test bed results. The further development of the ATHENA Interoperability framework aiming at categorising and integrating ATHENA solution components (project A4) will also provide valuable inputs for future ISO 15704 revision.

\section{ENTERPRISE MODELLING LANGUAGE (EML)}

Among various research components, Enterprise Modelling Language (EML) has a special position because of increasing attention to model-driven or model-based architecture and application developments.

\subsection{Initial result - UEML v1.0}

The concept of UEML was born in 1997 in the frame of ICEIMT (Torino conference) organised in cooperation with NIST. UEML thematic network project 
(UEML, 2001) was the first concrete action to develop UEML involving key Research Centres and some European tool providers in the domain of Enterprise Modelling. The aim of this first activity was to: (1) form an interest group of important Enterprise Modelling Stakeholder; (2) identify requirements on UEML and Enterprise Modelling in general; (3) define the first version of the UEML 1.0 meta model; (4) elaborate an UEML exchange format as the first prototype in order to analyse the feasibility of the UEML concepts.

The UEML 1.0 meta model was derived from the analysis of commonalities between the three involved Enterprise Modelling languages: GRAI, EEML and IEM. So for instance the GRAI GRID for decision support is not covered by the UEML 1.0. An initial set of UEML constructs (Berio, 2003) were identified as shown in Figure 3. The exchange of process models via the implemented XML format was mostly successful. However the exact transformation of the graphical data from one tool to the other was difficult to achieve.

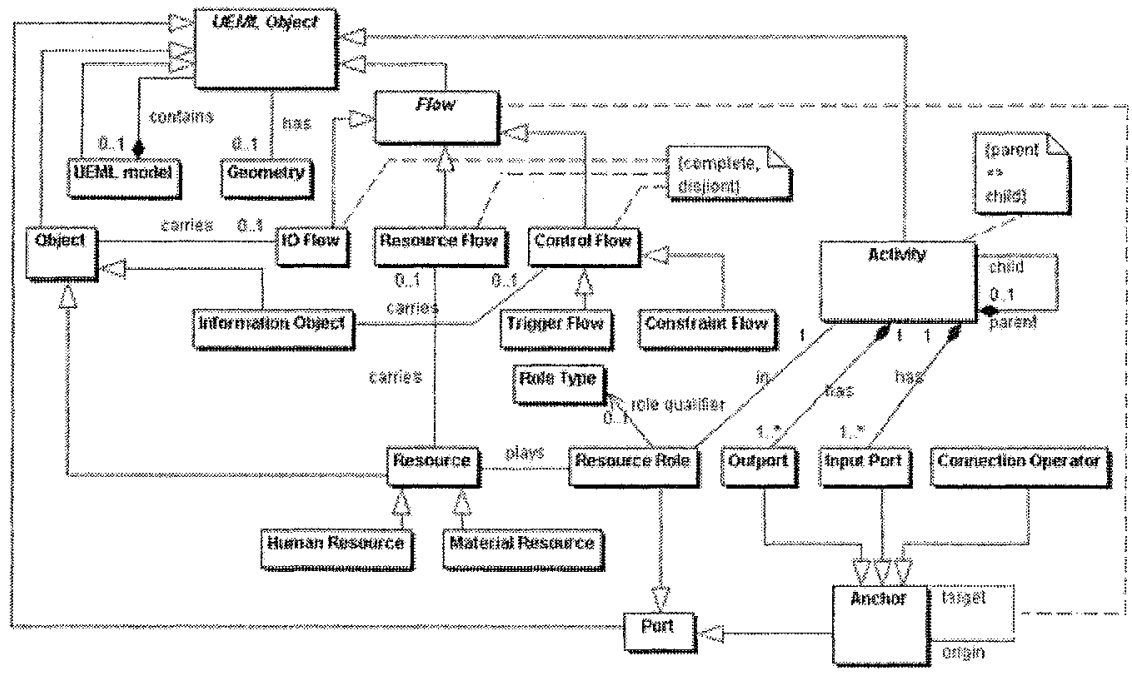

Figure 3. UEML constructs - UEML v1.0 meta model

\subsection{Use of UEML $v 1.0$ in ATHENA A1 project}

The ATHENA Al project (Knothe, 2004) will use experiences and results of the UEML Thematic Network Project in order to elaborate among others the Modelling Platform for Collaborative Enterprises (MPCE). The project is led by FhG-IPK of Berlin. Today there are three main points for adapting the approach to achieve enterprise modelling interoperability (Mertins et al., 2004) (also see Figure 4):

- Select and adapt a common Meta Meta Model. This approach will ensure easier mapping by common basic concepts without restricting single Enterprise Modelling languages. Possible useful concepts are MOF (Meta Object Facility), RDF (Resource Description Framework) or OWL (Web Ontology Language). Whereas MOF provides a rigid framework for the meta model extension, RDF is a language for representing information about resources in the World Wide Web. RDF is used for identifying elements by using Web identifiers (called Uniform 
Resource Identifiers, or URIs), and describing resources in terms of simple properties and property values. So the RDF language can be influence the principles implemented in the repository management system for finding modelling elements inside the repository. So the complexity of the interface to the modelling tools could be reduced. OWL is a W3C specification to define domain ontology's according to a formal description language. The advantage to RDF is the capability to define expressions similar to first order logic. For the extensibility of the POP* Repository in order to define domain oriented reference structures for easier model exchange this language could be a candidate for further analysis.

- Define a wide range repository structure for storing enterprise models. Common and non common modelling elements could be stored. So linked enterprise modelling tools must not cover the complete model. It should be possible to change only some dimensions of an enterprise model. The repository services have to ensure consistency of the enterprise model inside the repository structure by using reflective views.

- Analyse the existing enterprise modelling standards to implement the repository structure. E.g., EN/ISO 19440 or 19439 should influence the definition work. On the other hand the currently new emergent methodologies like BPDM (Business Process Definition Model) from OMG will be taken into account. The link of the repository to BPDM can enable direct links to the execution oriented levels. The objective here is to support execution of models parts, stored in the common repository. Especially the existing UML models will be useful for analysis.

A preliminary set of constructs focusing on process related concepts has been identified, based on the inputs from EN/ISO 19440, the OMG BPDM and UEML. These constructs will be refined and further extended to cover other concepts relating to interoperability of collaborative enterprises.

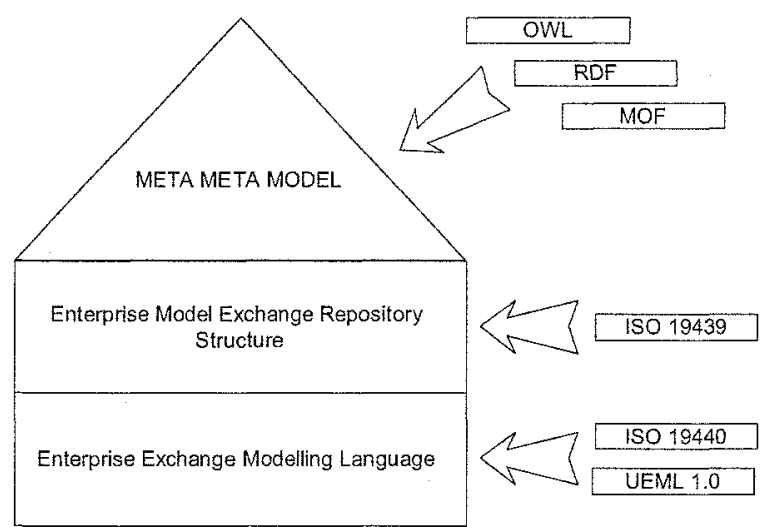

Figure 4: Athena A1 approach and related existing work that will influence the Exchange System development

The use of UEML in project A1 aims at tackling the interoperability problem between enterprise models and modelling tools (at higher abstraction level) providing a mapping mechanism. It also aims at vertical interoperability to allow 
generating workplaces from high abstraction enterprise models. Finally solutions provided by $\mathrm{A} 1$ should allow interoperability between workplaces so generated at run time level.

\subsection{Develop UEML v2.0 in INTEROP}

Besides of the use of UEML v1.0 in ATHENA project A1, within INTEROP Network of Excellence (Interop, 2003), UEML v1.0 is being further developed by WP5 (Common Enterprise Modelling Framework) led jointly by University of Torino and FhG-IPK of Berlin. Main objective of UEML V2.0 is to define constructs for modelling distributed enterprises for interoperability on the one hand, and on the other hand evaluate how the UEML can be used to support synchronisation of different distributed enterprise models. UEML v2.0 will be released at the month 18 (May 2005) and UEML v3.0 at the month 36 (November 2006). Furthermore, a strategy for 'UEML' extension and its assessment will be developed. Two main open issues/questions raised are (Berio, 2004): (1) Should UEML be an ontology for evaluating Enterprise Modelling Languages? (2) If UEML is not an ontology, which ontology should be used? Concerning the use of ontology, the State-of-the-Art indicated that existing ontology solutions which exhibit a high semantic adequacy such as MIT Process Handbook or Toronto Virtual Enterprise (TOVE) are too complicated for a practical and extensive industrial use. Current ontology languages are fairly weak in representing enterprise and business concepts (Ideas, 2003) As INTEROP WP 5 will only define some possible strategies new projects are needed for further development. Here the experiences of ATHENA A1 can be used in order to develop concepts that are suitable for the industry..

Another research activity relating to UEML v2.0 is currently performed by WP7 (led by GRAISOFT) in INTEROP. It aims to generate Customised Enterprise Application from enterprise models. The use of UEML v2.0 is expected to allow not only the mapping between enterprise models, but also providing transformation mechanism linking software application components to enterprise model content.

\section{CONCLUSION}

This paper has presented an overview on ATHENA Project and tentatively mapped ATHENA to ISO 15704. The mapping developed is rather straightforward using the most salient characteristics known today for each category, and is expected to be further refined. Globally speaking, the mapping is successful and ATHENA solution components fit well within ISO GERAM framework. However the mapping also encountered some terminology problem. On the one hand, terms used in ATHENA are not fully compliant with ISO 15704 (for example, tool in ATHENA has a broad meaning and not only refer to enterprise modelling tool). On the other hand, some terms used in ISO 15704 may lead to some misunderstanding (for example enterprise module and partial model). Nevertheless this mapping contributes to the use of ISO 15704 standard and a better categorisation of ATHENA project solutions.

\section{Acknowledgments}

This paper is partly funded by the E.C. through the ATHENA IP. It does not represent the view of the E.C., and authors are responsible for the paper's content. 
ATHENA IP is funded by the European Commission, under the $6^{\text {th }}$ Framework R\&D Programme, contract $n^{\circ}$ 507849. The authors thank and acknowledge the members of the ATHENA consortium: SAP (D), AIDIMA (E), Computas (NO), CR Fiat (I), DFKI (D), EADS (F), ESI (E), Formula (I), IPK (D), Graisoft (F), IC Focus (UK), Intracom (EL), LEKS (I), SINTEF (N), TXT (I), Univ. Bordeaux 1 (F), UNINOVA (POR), IBM (UK), SIEMENS (D).

\section{REFERENCES}

ATHENA (2004), Advanced Technologies for Interoperability of Heterogeneous Enterprise Networks and their Applications, FP6-2002-IST-1, Integrated Project Description of Work.

Berio, G. et al. (2003), UEML Deliverable D 3.1 Requirements analysis: initial core constructs and architecture, 2003.

Berio, G. (2004), Report on the received contributions from INTEROP WP5 Partners, Version 1.0, 10 April 2004.

Karlsen, D.; Lillehagen, F. (2004): Implementing the AKM technology.

Knothe, T., et al. (2004), ATHENA A1 project description, ATHENA project internal document, 2004.

IDEAS (2003), IDEAS Project Deliverables (WP1-WP7), Public Reports, WwW.ideas-road map.net

INTEROP (2003), Interoperability Research for Networked Enterprises Applications and Software, Network of Excellence, Proposal Part B, April 23, 2003.

ISO 15704 (2000), Industrial automation systems - Requirements for enterprisereference architectures and methodologies, ISO 15704:2000(E).

Mertins, K.; Knothe, T.; Zelm, M. (2004), User oriented Enterprise Modelling for Interoperability with UEML, the EMMSAD'04, RIGA, Latvia, June, 2004

OMG (2004), Meta Object Facility (MOF) Specification, http://www.omg.org/docs/formal/02-04-03.pdf

UEML (2001), UEML Thematic Network - Contract No: IST - 2001 - 34229, Description of Work.

W3C (2004), Resource Description Framework (RDF): Concepts and Abstract Syntax http://www.w3.org/TR/rdf-concepts/ 